\title{
Mechanical Properties of Al 25 wt. \% Cu Functionally Graded Material
}

https://doi.org/10.1515/secm-2019-0014

Received August 2, 2017; accepted November 10, 2018

\begin{abstract}
The present work refers to describe the effects of $\mathrm{Al}_{2} \mathrm{Cu}$ variations on various properties of thick-walled functionally graded (FG) cylindrical shell. Al-25 wt.\% $\mathrm{Cu}$ hypo-eutectic alloy ingot is melted and centrifugally casted to obtain high entropy FG composite. A series of microstructure examinations such as FESEM and EDX analysis were carried out to determine the distributions of constituent phases and elements. It is revealed that the maximum volume fraction of $\mathrm{Al}_{2} \mathrm{Cu}$ particle is reached near the inner surface with $35.7 \mathrm{Vol} . \%$ and then reduces gradually to $32.5 \mathrm{Vol} . \%$ at the outer surface of FG cylindrical shell. The effects of the variations $\mathrm{Al}_{2} \mathrm{Cu}$ along radial direction of FG tube are discussed through Vickers hardness, wear rate, coefficient of thermal expansion and compressive test measurements. The experimental results show that the wear and hardness are varied in graded manner which the highest wear resistance with wear rate of $9.1 \times 10^{-5} \mathrm{~g} / \mathrm{mm}^{2}$ and hardness with $153 \mathrm{HV}$ are found towards $\mathrm{Al}_{2} \mathrm{Cu}$ enriched zone or inner periphery. Moreover, the studied FG cylindrical shell shows drop $2.5 \%$ in yield stress and $4.5 \%$ in elastic modulus from intermediate to inner layers due to $\mathrm{Al}_{2} \mathrm{Cu}$ particles clustering in metal matrix.
\end{abstract}

Keywords: Coefficient of thermal expansion; Hardness; Horizontal centrifugal casting; Strength; Wear resistance

Aref Mehditabar, Gholam H. Rahimi: Department of Mechanical Engineering, Tarbiat Modares University, Tehran, Iran

^Corresponding Author: Seyed Ebrahim Vahdat: Department of Engineering, Ayatollah Amoli Branch, Islamic Azad University, Amol, Iran, E-mail: e.vahdat@iauamol.ac.ir

\section{Nomenclature}

\begin{tabular}{lc}
\hline Coefficient of thermal expansion & CTE \\
Rockwell C Scale Hardness & HRC \\
Module of Elastic & $E$ \\
Volume fraction & Vol. \\
Energy Dispersive X-ray spectroscopy & EDX \\
Volume fraction of $\mathrm{Al}_{2} \mathrm{Cu}(\theta$-phase $)$ & $V_{\theta} \%$ \\
Field Emission Scanning Electron Microscopy & $\mathrm{FESEM}$ \\
Volume Fraction of supersaturated Al $(\alpha$-phse $)$ & $V_{\alpha} \%$ \\
Functionally Graded Material & $\mathrm{FGM}$ \\
Wear Rate & $\mathrm{Wr}$ \\
X-Ray Diffraction & XRD \\
Vickers Hardness & $H V$ \\
Yield Stress & $\sigma_{y}$ \\
\hline
\end{tabular}

\section{Introduction}

The desire for long-term performance of structures in withstanding extreme temperature gradient through specific direction with maintaining integrity of the structure, has leaded in development of new class of advanced composite materials so-called functionally graded materials (FGMs). In this type of composite material, the properties are smoothly and continuously varied from one to the other surfaces by means of non-uniform distributions of reinforcement phase. Gradual changing of material properties along the specific direction, eliminates the corrosion, fatigue, fracture and local stress concentrations resulted from the abrupt changes of material properties in monolithic laminated composite material [1]. Accordingly, special processing is required to produce these smooth changes in properties in these kinds of materials. Several techniques for fabrication of FGMs components have been proposed such as melt processing, hot spraying duplicate, powder metallurgy, processing of polymer-based FGMs and etc. However, centrifugal casting method is the most efficient and affordable procedure that manufacturing can be performed with fewer processing steps.

Different alloying elements are applied to fabricate Albased FGM, such as Al-Ti, Al-Ni-Ti, Al-Cu, Al-Cu-Fe, Al$\mathrm{Mg}-\mathrm{B}, \mathrm{Al}-\mathrm{Ni}$ and $\mathrm{Al}-\mathrm{Zr}$. Among various kinds of aluminum 
metal matrix, Al-Cu casting alloy as an important class of light-weight materials has been found widespread use in aircraft structures and other engineering areas. The other

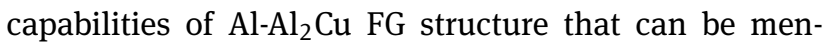
tioned are good specific strength and good wear resistance.

The microstructure formation is a key issue for understanding the behavior of FG materials. Therefore, a series of microstructure analysis are carried out to characterize the types of the phases and obtain the variations of constituent phases through thickness of FG tube. To accomplish these purposes, FESEM with aid of computer software (MATLAB code) that works on image analysis are employed to obtain the distributions of existing phases across the casting section. Until recently, many researches on FG Al-metal matrix fabricated through centrifugally casting method are carried out that are overviewed here. Duque et al. [2] investigated the microstructural behavior of FG Al-metal matrix reinforced with different volume fractions of $\mathrm{AlB}_{2}$ manufactured through centrifugal casting technique. Rajan et al. [3] processed FG Al (A356) $20 \% \mathrm{SiC}$ and (A390) $20 \% \mathrm{SiC}$ by vertical centrifugal casting technique for composite brake discs in order to augment the efficiency of braking performance. Lin et al. [4] systematically studied the distributions of the volume fractions and particles sizes of Al-Si-Mg FGM tube reinforced with insitu $\mathrm{Si} / \mathrm{Mg}_{2} \mathrm{Si}$ particles manufactured by centrifugal casting method. Al-19Si and Al-19Si-5Mg FG composites cylindrical shells were successfully centrifugally casted by Yanbo et al. [5]. In their research, distributions of microstructures, hardness and wear resistance for two kinds of FG tubes were compared and discussed. Wanatabe et al. [6] investigated the influences of process conditions such as $\mathrm{G}$ number and cast condition on the variations of microstructure and cooling rate in $\mathrm{FG}$ pipe made of $\mathrm{Al}^{-\mathrm{Al}_{2}} \mathrm{Cu}$ fabricated through centrifugal casting method. Wanatabe and Oike [7] carried out the microstructural study of $\mathrm{Al}^{-\mathrm{Al}_{2} \mathrm{Cu}}$ FGMs employing horizontal centrifugal casting method with different initial master ingots. In their work, three specimens from the initial master ingots for (1) $\mathrm{Al}-20^{\circ} /{ }_{0} \mathrm{Cu}$ (hypoeutectic)(2) $\mathrm{Al}-33 \% \mathrm{Cu}$ (eutectic)(3) $\mathrm{Al}-40 \% \mathrm{Cu}$ (hypereutectic) were utilized. The influences of processing parameters including die speed and pouring temperature on mechanical properties of Al-Si alloy produced by centrifugal casting using Taguchi technique was investigated by Shailesh et al. [8]. Radhika and Raghu [9] applied various reinforcements for FGM Al-based master alloy to demonstrate the comparative study of graded properties through the hardness and abrasive wear tests using centrifugal casting technique. Chenet et al. [10] utilized centrifugal casting method to fabricate FG composite by Al-Zn-Si as elemental alloy to illustrate relation between microstructure distributions of the composite and hardness and wear resistance along radial direction. El-Hadad et al. [11] focused on the fabrication of $\mathrm{Al}-\mathrm{Al}_{3} \mathrm{Ti} / \mathrm{Ti}_{3} \mathrm{Al}$ using a unique method of centrifugal casting procedure. The consequence of processing temperature on size, shape and distributions of the reinforcement particles and their influences on hardness variations were shown. FGMs $\mathrm{Cu}$-matrix tube reinforced with powder mixture of abrasive grains metal particles was successfully fabricated through centrifugal sintering-casting technique by Kunimine et al. [12]. Interaction between processing condition including sintering temperature, holding time and casting temperature and microstructure of specimens were examined. Soflaei and Vahdat [13] carried out microstructure evaluation bonding location and length determination of diffusion bond in bi-metal structure of steel-bronze. Vahdat [14] investigated the relation between particle size and volume fraction of intermetallic composition $\mathrm{Cu}_{6} \mathrm{Sn}_{5}$ on bulk hardness of $\mathrm{SnCu} 4 \mathrm{~Pb} 3$. A review of the available literatures and to the knowledge of the authors, there is vast potential for further research on development and optimization of Al$\mathrm{Cu}$ FGM as main and most applicable alloy in various engineering fields specially in sensitive and important industry of aerial section.

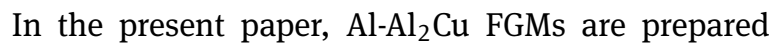
from $\mathrm{Al}-25 \mathrm{wt} . \% \mathrm{Cu}$ alloy using the horizontal centrifugal casting method. After production processing, a series of microstructure at submicron scales including FESEM tests are performed to determine the distributions of intermetallic compounds across the casting section. Moreover, miscellaneous tests at macro scales are carried out to achieve variations of parameters such as Vickers Hardness, coefficient of thermal expansion, elastic modulus, yield strength and wear rate as function of position across the radial direction. The main object of this work is to connect graded distribution of $\mathrm{Al}_{2} \mathrm{Cu}$ particles on the variations of aforementioned properties of FGM at various locations across the thickness.

\section{Material and Methods}

In this work, horizontal centrifugal casting equipment is applied to fabricate thick-walled $\mathrm{Al}_{-} \mathrm{Al}_{2} \mathrm{Cu}$ FG cylindrical shell. A schematic representation of horizontal centrifugal casting system is illustrated in Fig.1.

Characterizations of machinery components are described as follows. Electromotor 0.55 KW manufactured by DUTCHI NL company accompanied with convertor 200 


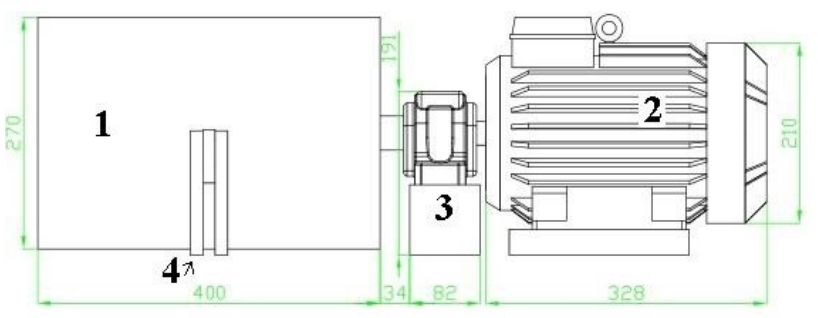

1-mold, 2-Electromotor with convertor, 3-main bearing, 4-roller bearing

Figure 1: Schematic diagram of horizontal centrifugal casting applied for fabricating $\mathrm{Al}_{-} \mathrm{Al}_{2} \mathrm{Cu} \mathrm{FGM}$, all dimension in millimeter

$V$ fabricated by TECO E310 company series were applied to regulate the rotational speed of mold. Steel is considered for material of mold and also geometrical properties of mold are assumed to be $12 \mathrm{~mm}$ in thickness $(t), 240 \mathrm{~mm}$ in length $(L)$ and $100 \mathrm{~mm}$ in inner diameter $(D)$ with $L / D$ equals to 1.2 .

Al-25 wt.\% $\mathrm{Cu}$ with the chemical compositions listed in Table 1 were utilized for the production of $\mathrm{Al}^{-\mathrm{Al}_{2} \mathrm{Cu}} \mathrm{FG}$ tube.

$5 \mathrm{~kg}$ of commercial pure $\mathrm{Cu}$ ingot and $17 \mathrm{~kg}$ of commercial $\mathrm{Al}$ ingot with $8.2 \mathrm{wt} . \%$ of $\mathrm{Si}$ and $2.3 \mathrm{wt} . \%$ of $\mathrm{Cu}$ as major alloy element were taken as raw materials. As first step towards producing centrifugally casted $\mathrm{Al}^{-} \mathrm{Al}_{2} \mathrm{Cu}$ FGM, $\mathrm{Cu}$ ingot was melted at $1300^{\circ} \mathrm{C}$ in the crucible made of graphite by using gasoil flame furnace taking time $1 h$. The $\mathrm{Al}$ ingot was superheated to $750^{\circ} \mathrm{C}$ in the crucible made of graphite by using gasoil flame furnace taking time $15 \mathrm{~min}$. When two different ingredient alloys achieved the melt reached ideal temperature, these are taken from the furnaces and mixed to provide the composite molten melt. The composite melt must be stirred up and temperature of melt is kept at $650^{\circ} \mathrm{C}$ to avoid the pre solidification. The prepared composite melt was directly driven through pouring hole into spinning metal mold which is fitted to the shaft of the horizontal centrifugal casting machine. According to Eq. (1), the rotational speed of mold was regulated at $1000 \mathrm{rpm}$ as follows [14]:

$$
\omega \geq \sqrt{ }(g /(R-t))
$$

Where, $\mathrm{g}$ is $9.8 \mathrm{~m} / \mathrm{sec}^{2}, r$ is inner radius (free surface) of product in meter, $R$ is outer radius of product (or inner radius of mold) in meter, $t$ is thickness of product in meter and $\omega$ is rotation speed of mold in rotation per seconds for production of sound cast with thickness of $t$. The rotation lasted for nearly $15 \mathrm{~min}$ of casting, and then the mold was turned off. Consequently, when the component was cooled in air and complete solidification occurred, it was pulled out from the mold shortly afterward.

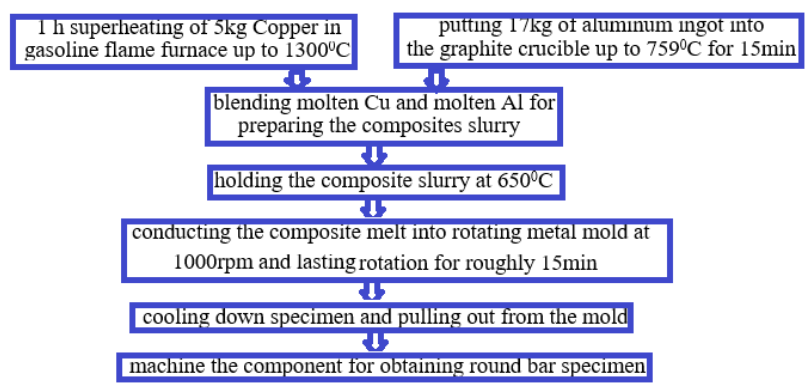

Figure 2: Schematic diagram of fabrication procedure

The whole process steps are summarized in Fig. 2. When the operation is finished and the raw hollow cylinder was prepared through centrifugal casting technique, in the case of industrial application, component must be satisfactorily machined off. The resultant machined component has details dimensions of $200 \mathrm{~mm}$ in outer diameter and $1000 \mathrm{~mm}$ in length and $12 \mathrm{~mm}$ in wall thickness. The essential behavior of FGM depends on microstructure characterization or variations of the intermetallic compound with respect to the location within cast section which are discussed in the next section.

\section{Results and Discussion}

In this research, to ensure the correctness of results, the laboratories certified by standard organization were applied. The quantitative results are presented in Table 2, and details are discussed in the following sections of this paper.

\subsection{FESEM results}

FESEM micrograph of $\mathrm{Al}^{-\mathrm{Al}_{2} \mathrm{Cu}} \mathrm{FGM}$ tube fabricated through the centrifugal casting method utilizing Al-25 wt.\% $\mathrm{Cu}$ initially alloy, at different locations across the thickness are demonstrated in Fig. 3(a-f). It must be noted that white phases indicate reinforcement particles of $\mathrm{Al}_{2} \mathrm{Cu}$ and black region determines $\alpha$-Al phase. According to Fig. 3(a-f), more $\mathrm{Al}_{2} \mathrm{Cu}$ particles exist in the region close to the inner layers of the tube compared to layers close to outer layers. It is also found that in the region close to the outer peripheries, particles sizes of $\mathrm{Al}_{2} \mathrm{Cu}$ become coarser and platelet form, when those are compared to the region close to inner peripheries.

Another interesting point to be noted from Fig. 3(a-f) is that the intermetallic compound particles of $\mathrm{Al}_{2} \mathrm{Cu}$ are significantly finer and more uniformly distributed and show 
Table 1: Chemical composition of FGM ingot

\begin{tabular}{ccccccccc}
\hline Element & $\mathrm{Al}$ & $\mathrm{Cu}$ & $\mathrm{Si}$ & $\mathrm{P}$ & $\mathrm{S}$ & $\mathrm{K}$ & $\mathrm{Ca}$ & $\mathrm{Zn}$ \\
\hline Wt. $\%$ & Balance & 25.248 & 6.228 & 0.034 & 0.110 & 0.657 & 0.374 & 0.160 \\
\hline
\end{tabular}

Table 2: Results of $E, \sigma_{y}, V_{\theta} \%, H V, C T E$ and $W r$

\begin{tabular}{ccccccc}
\hline Layers $\mathrm{mm}$ & $\begin{array}{c}E \\
(\mathrm{MPa})\end{array}$ & $\sigma_{y}(\mathrm{MPa})$ & $V_{\theta} \%$ & $\alpha \times\left(1 /{ }^{0} \mathrm{C}\right) 10^{-6}$ at $115^{\circ} \mathrm{C}$ & $H V$ & $\operatorname{Wr}\left(\mathrm{g} / \mathrm{mm}^{2} \times 10^{-6}\right)$ \\
\hline 8-12 Outer & 7534 & 395 & 32.5 & 18.7 & 150 & 11.62 \\
4-8 middle & 8461 & 390 & 33.3 & 19.1 & 151 & 9.51 \\
0-4 Inner & 8076 & 380 & 35.7 & 19.3 & 153 & 9.10 \\
\hline
\end{tabular}

less particle clustering in the regions close to inner layers compared to locations close to outer layers. The following formation of graded composition in the FGM can persuade the $\mathrm{Al}_{2} \mathrm{Cu}$ variations across the thickness. In spite of the fact that $\mathrm{Al}_{2} \mathrm{Cu}$ density is $4.4 \mathrm{~g} / \mathrm{cm}^{3}$ and density of molten $\alpha-\mathrm{Al}$ is $2.369 \mathrm{~g} / \mathrm{cm}^{3}$ (at $650^{\circ} \mathrm{C}$ ) and centrifugal force can conduct $\mathrm{Al}_{2} \mathrm{Cu}$ towards outer periphery but the point must be under consideration is that the melt pointing of $\mathrm{Al}_{2} \mathrm{Cu}$ is $535^{\circ} \mathrm{C}$, whereas the melt pointing of $\alpha$ - $\mathrm{Al}$ is $660^{\circ} \mathrm{C}$, since the tube is rapidly solidified from outer to inner walls due to cooling effect of mold, the primary $\alpha$-Al captured before migrating towards the inner layer. Consequently, more $\mathrm{Al}_{2} \mathrm{Cu}$ particles in the ring's inner regions are found compared to the ring's outer regions of thick-walled FG cylindrical shell. There is good correlation between present experimental results and the results reported in reference [15].

Quantitative values of volume fraction of $\theta$-phase $V_{\theta} \%$ and volume fraction of $\alpha$-Al phase $V_{\alpha} \%$ as function of thickness from the inner to outer peripheries of the tubes are calculated by applying computer software (MATLAB code) that works on image analysis. The graded distributions of $V_{\alpha} \%$ and $V_{\theta} \%$ are depicted in Fig. 4. The $V_{\theta} \%$ in the $\mathrm{Al}-25 \mathrm{wt} . \% \mathrm{Cu} \mathrm{FG}$ tube decreases gradually from $35.7 \mathrm{Vol} . \%$ to $32.5 \mathrm{Vol} . \%$ which belongs to the region to the inner and outer surfaces of FG cylinder, respectively. In contrast to variations of $V_{\theta} \%$, the $V_{\alpha} \%$ enhances from the inner to outer peripheries of FG cylindrical shell. Variations of weight percentages of $\mathrm{Al}$ and $\mathrm{Cu}$ as main elements in thick-walled FG cylindrical shell in various zones from the inner to outer walls calculated from EDX analysis which is presented in Fig. 5. It is found that $\mathrm{Cu}$ weight percentage monotonically decreases towards ring's outer region that highest value is $17.26 \mathrm{wt} . \%$ and smallest value is $16.06 \mathrm{wt} . \%$ located at the inner and outer peripheries, respectively. The experimental results from Fig.5 persuade the experimentally results from Fig. 4 which means by increasing $\mathrm{Cu}$ content towards the region close to inner layer of $\mathrm{Al}_{-} \mathrm{Al}_{2} \mathrm{Cu}$ FGM tube, opportunities for formation of $\mathrm{Al}_{2} \mathrm{Cu}$ particles will be augmented.

In the remaining parts of paper, it becomes ascertained that how the distributions of reinforcing particles contribute the overall mechanical, physical and tribological properties of FG alloy.

\subsection{Hardness results}

Vickers hardness testing was performed according to ASTM E92 in laboratory certified by iranian national standards organization (RMRC), Tehran, Iran. Fig. 6 illustrates the values of hardness of FGM tube fabricated from Al-25 wt.\% $\mathrm{Cu}$ alloy at different locations in radial section. It is obvious that the magnitude of hardness increases from the outer to inner walls of FGM cylinder which highest level of hardness with $153 \mathrm{HV}$ was occurred in the inner layer and smallest belongs to the outer layer with $150 \mathrm{HV}$. The Vickers hardness changes corresponds well with the radial distribution of $\mathrm{Al}_{2} \mathrm{Cu}$ intermetallic compounds, since the density and hardness of the $\mathrm{Al}_{2} \mathrm{Cu}$ particle is much larger than those of supersaturated $\alpha$-Al phase. Consequently, the same trends of $\mathrm{Al}_{2} \mathrm{Cu}$ variation must be took place to hardness variations.

\subsection{Coefficient of thermal expansion results}

Coefficient of thermal expansion examination was carried out at esteemed European Union University (Silesian University of Technology, Gliwice, Poland). Fig. 7 demonstrates the variations of coefficient of thermal expansion at various temperature ranges for locations at $0-4 \mathrm{~mm}$, 4$8 \mathrm{~mm}$ and 8-12 $\mathrm{mm}$ away from the inner wall of FG tube. The coefficient of thermal expansion gradually changes corresponds to the variation in $\mathrm{Al}_{2} \mathrm{Cu}$ content. The more 

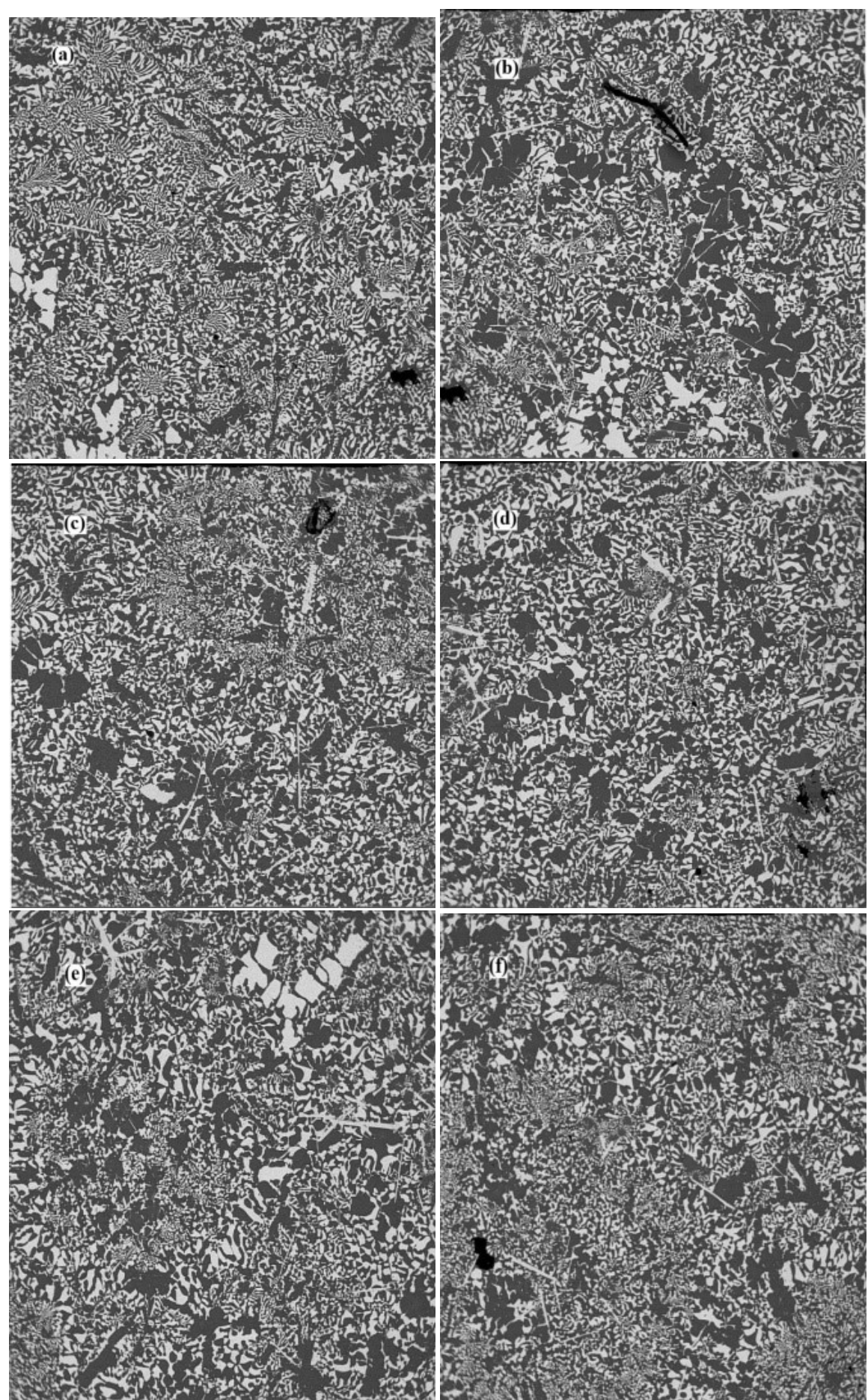

Figure 3: The typical FESEM microstructures of the $\mathrm{Al}-\mathrm{Al}_{2} \mathrm{Cu}$ FGM cylindrical shell at different zones which are (a) 0-2 mm, (b) 2-4 mm, (c) 4-6 mm, (d) 6-8 mm, (e) 8-10 mm, (f) $10-12 \mathrm{~mm}$, from the inner surface along the radial direction. 


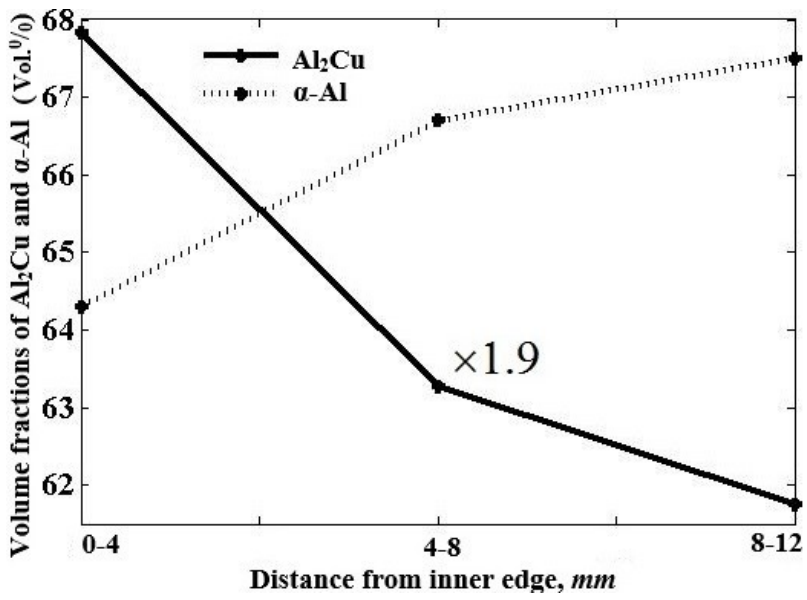

Figure 4: $\mathrm{V}_{\theta} \%$ and $\mathrm{V}_{\alpha} \%$ distribution of thick FGM cylindrical shell along radial direction from inner to outer walls

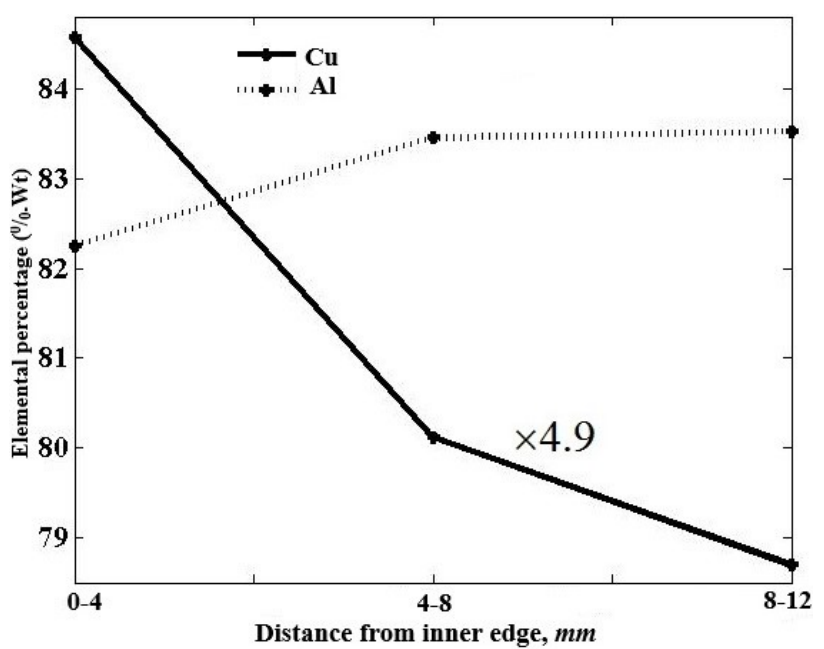

Figure 5: Distribution of $\mathrm{Cu}$ and $\mathrm{Al}$ along radial direction in the $\mathrm{Al}-$ $\mathrm{Al}_{2} \mathrm{Cu}$ FGM thick cylindrical shell measured by EDX analysis

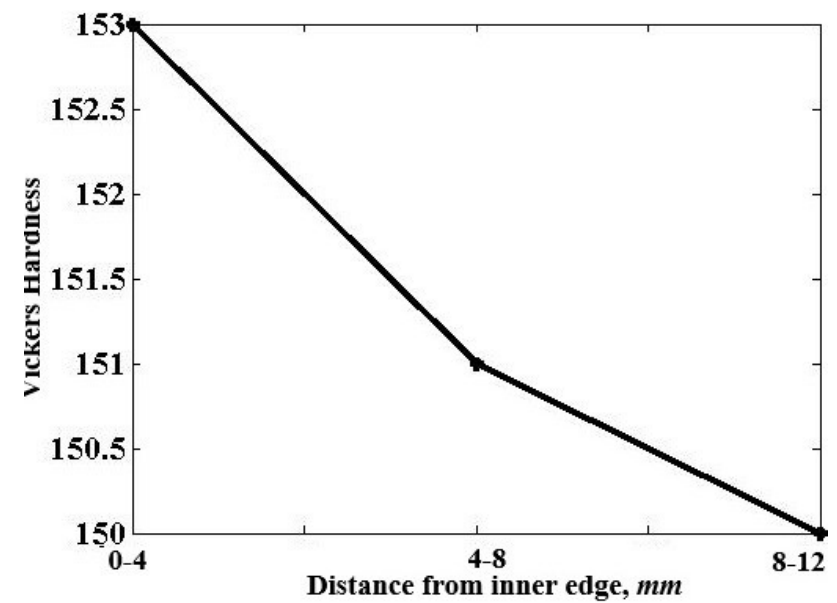

Figure 6: Variation of Vickers hardness values along radial direction for $\mathrm{Al}^{-\mathrm{Al}_{2}} \mathrm{Cu}$ thick $\mathrm{FGM}$ cylindrical shell

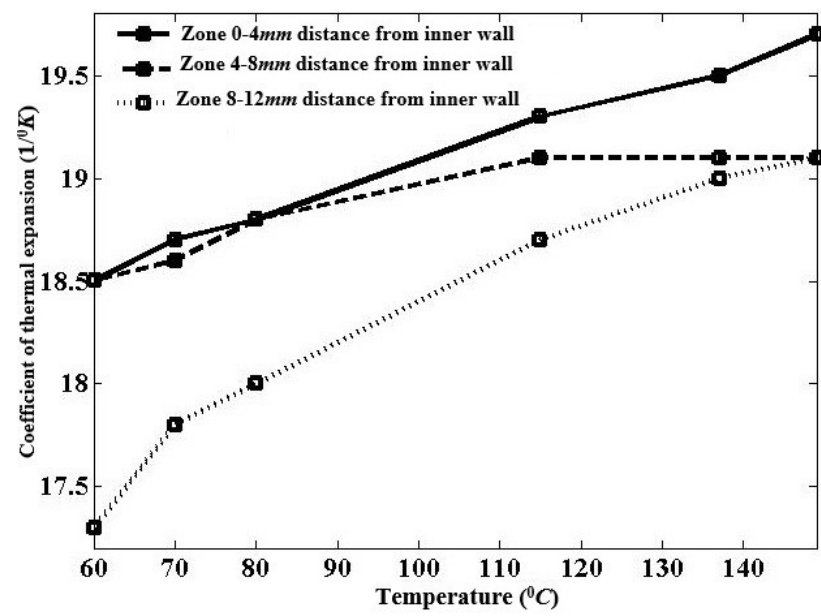

Figure 7: Variation of CTE with temperature for different section of thick FGM cylindrical shell along the radial direction

the content of $\mathrm{Al}_{2} \mathrm{Cu}$ causes an increase in coefficient of thermal expansion values of specimen. This is due to the fact that the coefficient of thermal expansion of functionally composite is sum of the reinforcement part $\left(\mathrm{Al}_{2} \mathrm{Cu}\right.$ precipitation) with coefficient of thermal expansion equals to $8.263 \times 10^{-5} \mathrm{~K}^{-1}[16]$ and metal matrix part (supersaturated $\alpha$-Al) with coefficient of thermal expansion equals to $2.4 \times 10^{-5} \mathrm{~K}^{-1}$ [17], consequently increasing $V_{\theta} \%$ from the outer to inner walls of FG tube leading to increases in coefficient of thermal expansion of FG metal matrix composite. It is worth to note that during coefficient of thermal expansion evaluation, temperature was from $60^{\circ} \mathrm{C}$ to $150^{\circ} \mathrm{C}$ at heating rate of $1^{\circ} \mathrm{K} / \mathrm{s}$.

\subsection{Elastic modulus $(E)$ and yield strength $\left(\sigma_{y}\right)$ results}

The compressive tests were performed to achieve the representative stress-strain curves for three tested sections along the radial direction as the corresponding curves are shown in Fig. 8(a-e).

The elastic modulus was calculated as the initial slope of the straight line that touches curve where in linearity between stress and strain is governed. The yield stress is the point on the stress-strain curve where the linear state (elastic deformation range) is transmitted to the nonlinear state (plastic deformation range). With this explanation, yield stress and elastic modulus as function of distance from the inner edge of FG cylindrical shell are plotted in Fig. 9 and Fig. 10, respectively. Fig. 9 indicates that the yield stress of thick-walled FG cylindrical shell decreased from the outer surface with $395 \mathrm{MPa}$ to the inner surface with $380 \mathrm{MPa}$ by 
increasing $V_{\theta} \%$ from outer wall with $32.5 \mathrm{Vol} .{ }^{0} \%$ to inner wall with $35.7 \mathrm{Vol} .{ }^{\circ} \%$. The compressive yield strength of $\mathrm{Al}_{2} \mathrm{Cu}$ is about $875 \mathrm{MPa}$ [18] and $\alpha$-Al phase is about $98 \mathrm{MPa}$ [16] and therefore increasing $\mathrm{Al}_{2} \mathrm{Cu}$ content causes an increase in $\sigma_{y}$ of FG tube, whereas it causes to falling of $\sigma_{y}$ value. A drop in $\sigma_{y}$ of FG tube from the outer to inner surfaces of thick-walled FG cylindrical shell can be attributed to Chawla phenomenon [19].

The presence of voids due to agglomeration of reinforcement particles at higher than those of optimum of $V_{\theta} \%$ cause incompatibility between the matrix, interface and reinforcement and consequently dropping of the resulted FGM yield stress occurred. There is good consistency between present results in Fig. 9 and the results reported in reference [20]. The variations of elastic modulus of thick-walled FG cylindrical shell throughout the thickness have been depicted in Fig. 10. From the experimental results in Fig. 11, it has been revealed that the effects of $\mathrm{Al}_{2} \mathrm{Cu}$ on elastic modulus $(E)$ is limited up to a certain value of $V_{\theta} \%$ which means the value of $E$ can be improved up until reaches the optimum value. The elastic modulus of $\mathrm{Al}_{2} \mathrm{Cu}$ is $104.5 \mathrm{GPa}$ [21] and elastic modulus of $\mathrm{Al}$ is 73 $\mathrm{GPa}[16]$ and therefore increasing $\mathrm{V}_{\theta} \%$ from the intermediate (4-8 $\mathrm{mm}$ away from the inner edge) to inner layers (0-4 $\mathrm{mm}$ away from the inner edge) of the FG tube normally can cause an increase in the elastic modulus of resulted composite. As one can see from corresponding Fig. 10, negative gradient from the intermediate to inner layers is revealed. This phenomenon known as Chawla can be justified as discussed earlier for the corresponding results of $\sigma_{y}$ in Fig. 9. It is worth to mention that optimum value for elastic modulus of studied FG tube is lower than $32.5 V_{\theta} \%$. The elastic modulus of the FG is attributed to compatibility between reinforcement content, characteristics of interface bonding between adjacent atomic planes which means increasing the amount of reinforcement particles from designated value, the tendency of particle clustering can be increased and subsequently the conditions for formations of voids and cavities are increased.

Hence, the aggregation of reinforcement at higher optimum values and formation of continuous layer dictate the nature of transition from reinforcement particle enriched to depleted regions. Fig. 10 displays that the highest magnitude of $E$ is $8.46 \mathrm{GPa}$ and lowest value is $7.53 \mathrm{GPa}$ that occurred in 4-8 $\mathrm{mm}$ and 8-12 $\mathrm{mm}$ away from inner surface of the tube, respectively.

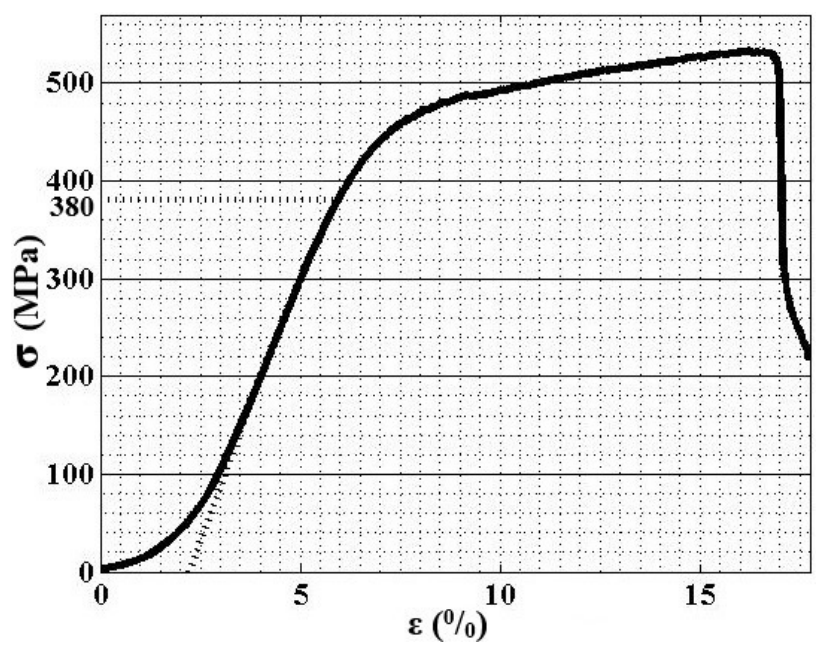

(a)

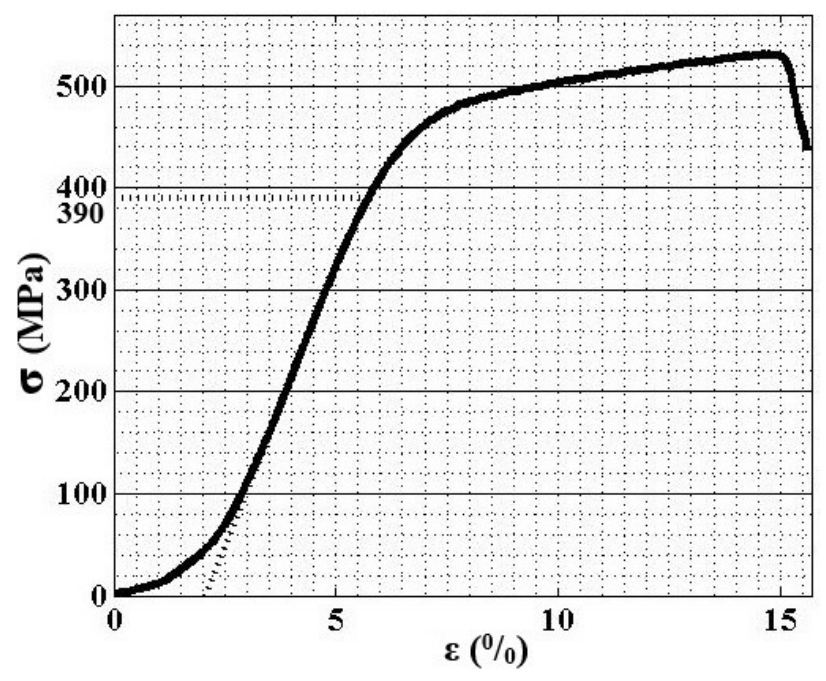

(b)

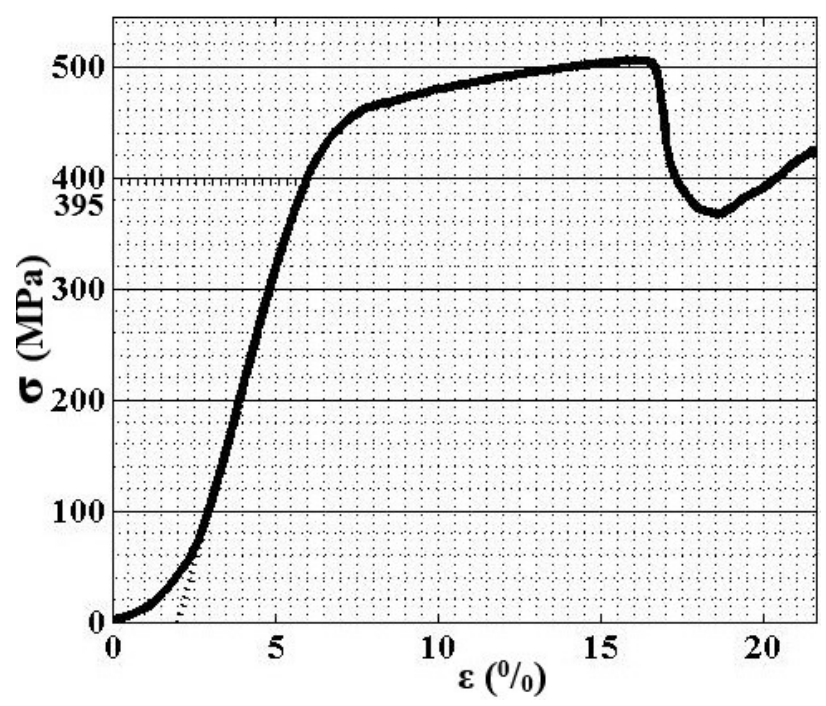

(c)

Figure 8: Corresponding stress-strain curves of $\mathrm{Al}_{-} \mathrm{Al}{ }_{2} \mathrm{Cu} \mathrm{FGM}$ from compressive test at different section (a) 0-4 mm, (b) $4-8 \mathrm{~mm}$, (c) 8-12 $\mathrm{mm}$, away from inner wall of the cylinder 


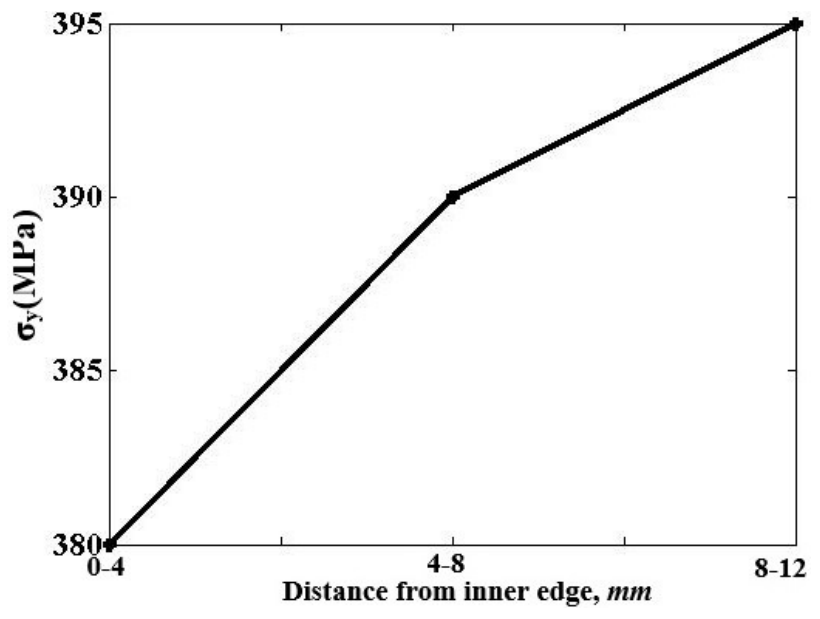

Figure 9: Variation of $\sigma_{y}$ along the radial direction from inner to outer wall of thick FGM cylindrical shell

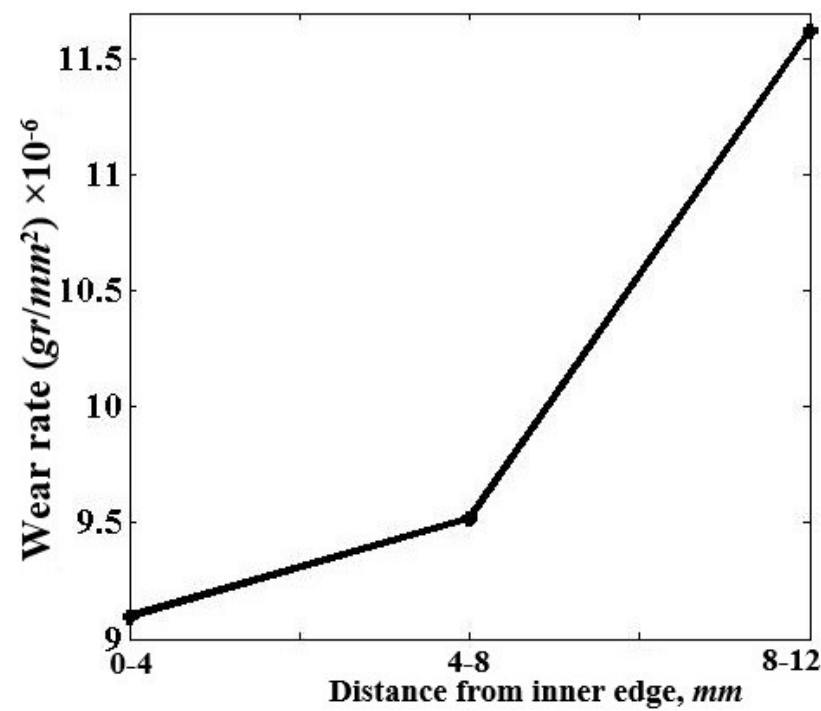

Figure 11: Variation of the $W r$ along the radial direction from inner to outer walls of thick FGM cylindrical shell under fixed normal load $\left(F_{N}\right)$ of $40 \mathrm{KN}$ at linear sliding velocity $\left(S_{V}\right)$ of $6.35: \mathrm{cm} / \mathrm{s}$ and sliding distance $\left(S_{m}\right)$ of $\sim 440 \mathrm{~m}$

\subsection{Sliding wear test results}

The increase of tribological property is one of the major concerning issues of FG materials for mechanical engineering designers. Dry sliding tests have been carried out using computerized pin-on-disc wear testing machine under ambient conditions room temperature and 35\% relative humidity. AISI52100 steel pin with hardness of 64 HRC have been used as rotating counter surface. The sample was cut in to slab shape of $2.4 \mathrm{~cm} \times 2.4 \mathrm{~cm}$ and $2 \mathrm{~mm}$ in thickness by wire-cut electrical discharge to obtain region in three section of 0-4 $\mathrm{mm}, 4-8 \mathrm{~mm}$ and 8-12 $\mathrm{mm}$ away from the inner layer. The test performed using fixed normal load $\left(F_{N}\right)$ of $40 \mathrm{KN}$ at linear sliding velocity $\left(S_{V}\right)$ of $6.35 \mathrm{~cm} / \mathrm{s}$ and sliding distance $\left(S_{m}\right)$ of $\sim 440 \mathrm{~m}$. In this paper, the estimation of wear rate is based on Eq. 2:

$$
W r=\Delta m / A
$$

Where, $W r$ represents wear rate, $\Delta m(g)$ is the mass loss calculated by weighting sample before and after test and also $A\left(\mathrm{~mm}^{2}\right)$ is specimen's surface contact area. Fig. 11 demonstrates the results of the evaluated wear rate for Al$25 \mathrm{wt} . \% \mathrm{Cu}$ centrifugally casted as function of radial distance. According to Fig. 11, the inner layer (the $\mathrm{Al}_{2} \mathrm{Cu}$ particles rich zone) shows the highest wear resistance with wear rate equals to $9.10 \times 10^{-5} \mathrm{~g} / \mathrm{mm}^{2}$ compared to other sections along the FG cylindrical shell. It has been proven that there is consistency between reinforcement content, hardness and wear rate. According to experimental results in Fig. 3(a-b), the reinforcement particles in the inner layer
Figure 10: Variation of $E$ along the radial direction from inner to outer walls of thick FGM cylindrical shell 

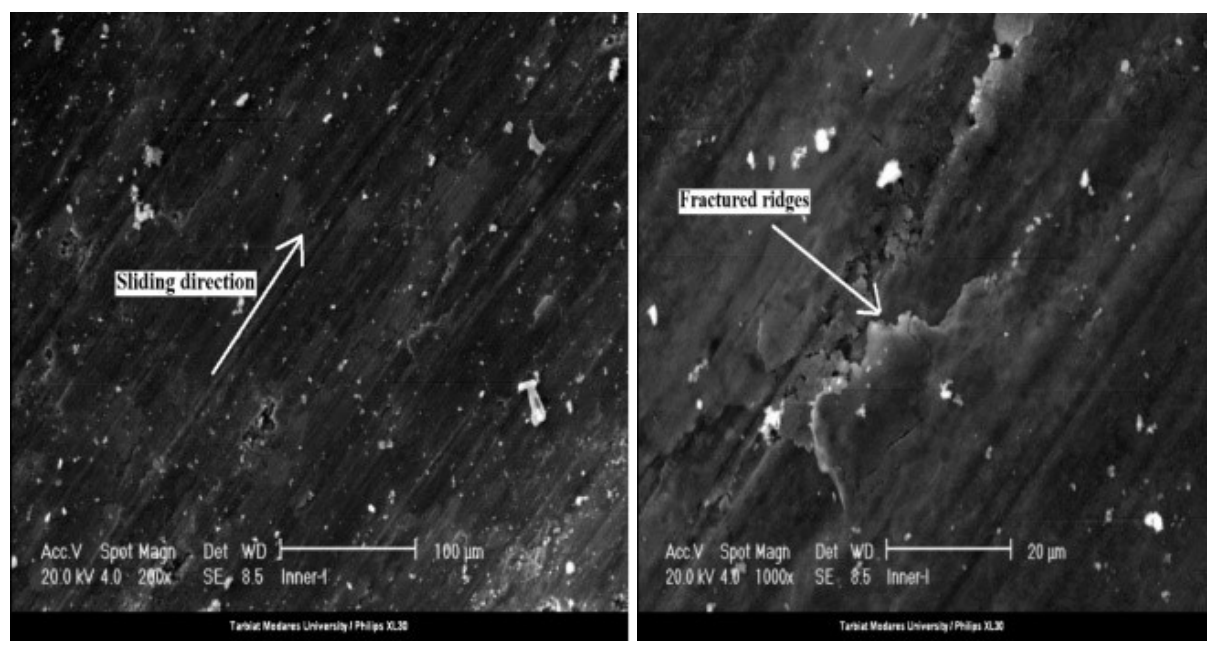

(a)

(b)
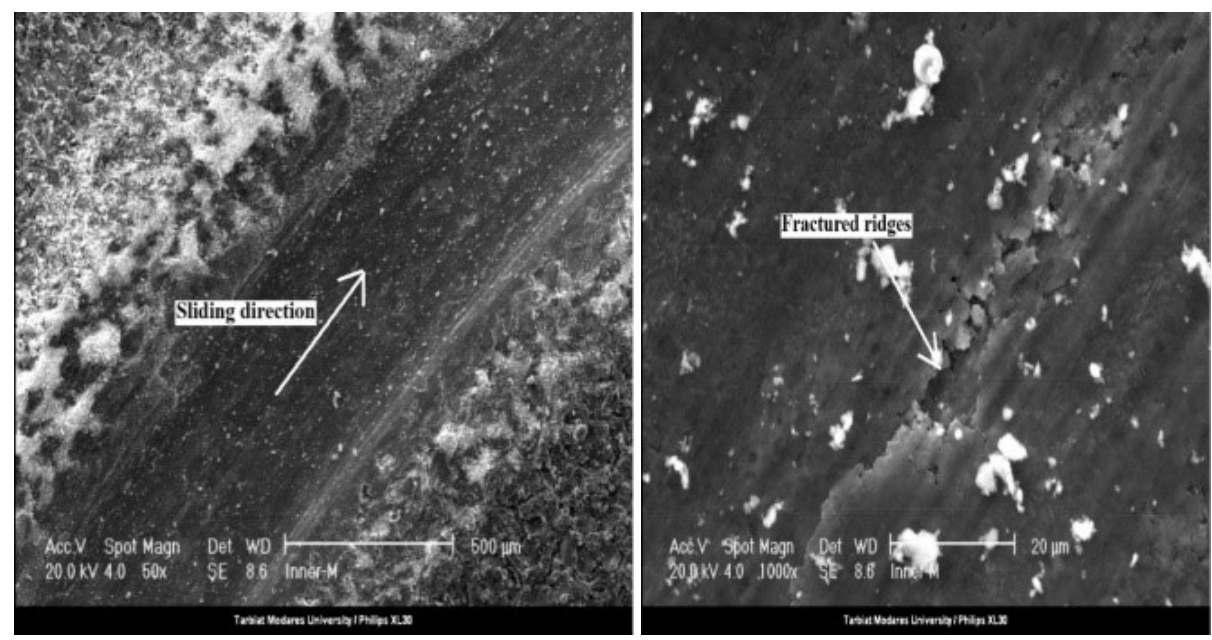

(c)

(d)
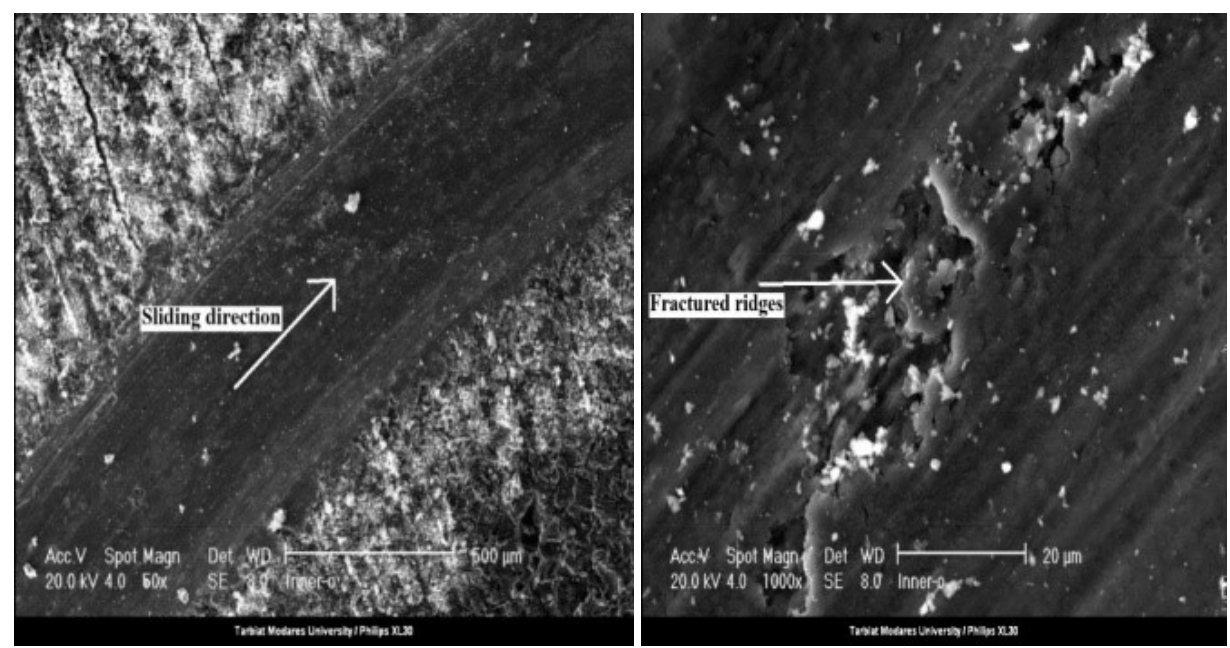

(e)

(f)

Figure 12: SEM Philips XL30 micrographs of worn surfaces of specimens at the end of wear test, carried out at linear sliding velocity $\left(\mathrm{S}_{V}\right)$ of $6.35 \mathrm{Cm} . \mathrm{s}^{-1}$ and under fixed normal load $\left(F_{N}\right)$ of $40 \mathrm{kN}$ in different test sections (a) and (b) sliding direction and sub-surface cracking for section 0-4 mm away from inner edge of FGM cylinder, respectively, (c) and (d) sliding direction and sub-surface cracking for section 4$8 \mathrm{~mm}$ away from inner edge of FGM cylinder, respectively, (e) and (f) sliding direction and sub-surface cracking for section 8-12 mm away from inner edge of FGM cylinder, respectively. 
are uniformly and finely distributed and also occupy dominant position with $35.7 \mathrm{Vol} \%$. Hence, it leads the layer in distance between 0-4 mm away from the inner edge to have the highest hardness (153 HV) and wear resistance (wear rate equals to $9.10 \times 10^{-5} \mathrm{~g} / \mathrm{mm}^{2}$ ).

\subsection{Wear debris results}

The salient features of worn-out surfaces and the morphology of generated collected wear debris were characterized by SEM Philips XL30 and EDX analysis in order to identify the operative wear mechanisms. Fig. 12(a-f) shows the SEM micrograph of the worn-out surfaces of inner, intermediate and outer layers of $\mathrm{Al}^{-\mathrm{Al}_{2}} \mathrm{Cu}$ FGM tube. The micrograph results of worn-out surfaces show that the predominant wear mechanism is abrasive and there is no adhesive mechanism. According to Fig. 12(a-f), the worn- out surface of the inner layer appears considerably smoother than that of other layers which is in good agreement with highest level of hardness and wear resistance in Fig. 6 and Fig. 11. From Fig. 12(a-f), it can be understood that no plastic deformation can be observed and therefore the structure stands mostly in the form of a ductile material which extraordinarily confronts the stresses during dry sliding wear test. Fig. 13 show the nature, size and morphology of the generated wear debris during wear test using SEM micrograph images under fixed normal load $\left(F_{N}\right)$ of $40 \mathrm{KN}$ at linear sliding velocity $\left(S_{V}\right)$ of $6.35 \mathrm{~cm} / \mathrm{s}$. The observation from Fig. 13 indicates that as result of brittle structure, the wear debris do not show any plastic deformation. The approximate sizes of wear debris particles are between $162 \mu \mathrm{m}$ and $55 \mu \mathrm{m}$.

From the reported XRD analysis results (Fig. 14) the investigated wear debris contains $\mathrm{Al}$ as main element and a small amount of $\mathrm{Cu}$ and $\mathrm{Si}$ and also negligible amount of $\mathrm{Mg}$ and $\mathrm{K}$ which these elements are combined with oxygen.

\section{Conclusion}

In the present research, the fabrication of thick-walled $\mathrm{Al}$ $\mathrm{Al}_{2} \mathrm{Cu}$ FG cylindrical shell from Al-25 wt. $\% \mathrm{Cu}$ alloy was conducted applying horizontal centrifugal casting technique. Compositional graded was created by segregation of particles due to relative melting points differences of the constituent phases and existing of centrifugal force. To understand the FGM behavior, microstructure study by FESEM tests was performed to obtain the distributions of intermetallic compounds across the radial direction. To il-

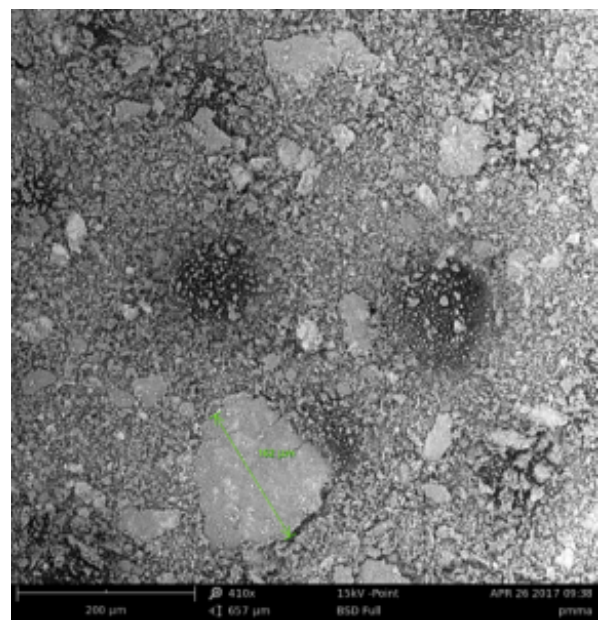

(a)

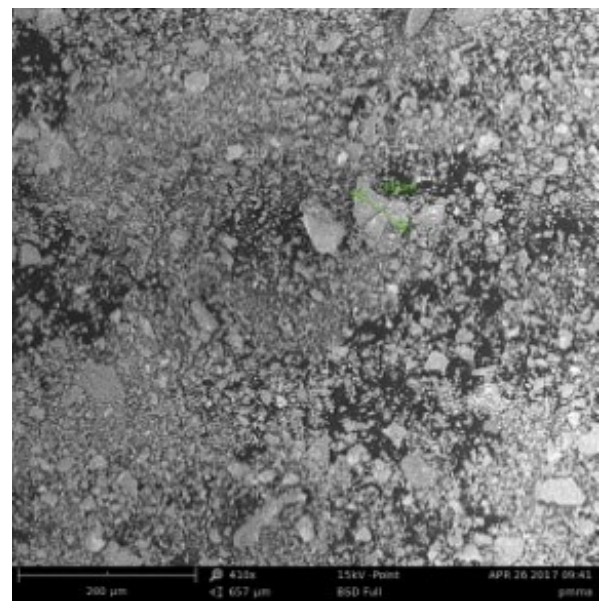

(b)

Figure 13: Detailed features of collected wear debris generated during the wear test from SEM Philips XL30 micrograph analysis under fixed normal load $\left(F_{N}\right) 40 \mathrm{kN}$ and at linear sliding velocity $\left(S_{V}\right)$ of $6.35 \mathrm{~cm} / \mathrm{s}$

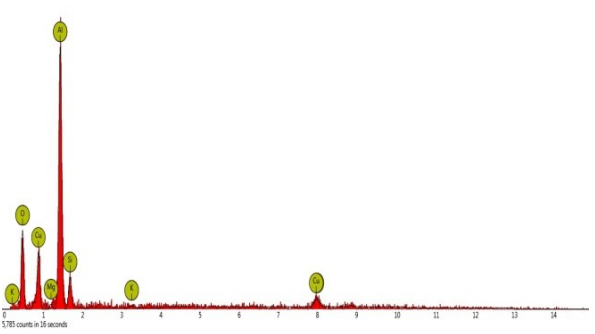

Figure 14: XRD results of the generated wear debris under fixed normal load $\left(F_{N}\right) 40 \mathrm{kN}$ and at linear sliding velocity $\left(S_{V}\right)$ of $6.35 \mathrm{~cm} / \mathrm{s}$

lustrate the effects of $V_{\theta} \%$ on properties at macroscales, various tests with different apparatuses were carried out to measure the variations of graded mechanical, physical, tribological properties and Vickers hardness across 
the thickness. The important findings of the present investigation are:

1. It was shown that $V_{\theta} \%$ increased from the outer layer to inner layer that statistically report was $32.5 \mathrm{Vol} . \%$ to 35.7 Vol.\%, respectively.

2. The experimental results of coefficient of thermal expansion have been demonstrated that the change of coefficient of thermal expansion of thick-walled Al$\mathrm{Al}_{2} \mathrm{Cu}$ FGMs cylindrical shell is related to the precipitations of $\mathrm{Al}_{2} \mathrm{Cu}$. The addition of $\mathrm{Al}_{2} \mathrm{Cu}$ from the outer layer (32.5 $\mathrm{Vol} . \%$ ) to the inner layer (35.7 $\mathrm{Vol} . \%$ ) caused an increase in coefficient of thermal expansion of FG tube at the temperature range between $60^{\circ} \mathrm{C}$ to $150^{\circ} \mathrm{C}$.

3. As expected, at the inner layer of $\mathrm{FG}$ tube which contains highest $V_{\theta} \%$, the studied advanced composite exhibits the highest hardness with $153 \mathrm{HV}$ and wear resistance with wear rate equals to $9.10 \times 10^{-5} \mathrm{~g} / \mathrm{mm}^{2}$.

4. Unlike other distributions of material properties of $\mathrm{FG}$ tube, the effects of $\mathrm{Al}_{2} \mathrm{Cu}$ particles on elastic modulus and yield strength of thick-walled $\mathrm{Al}^{-\mathrm{Al}_{2}} \mathrm{Cu} \mathrm{FGM}$ cylindrical shell was limited up to certain value of $V_{\theta} \%$. The optimum $V_{\theta} \%$ for studied FGM was lower than 32.5 Vol.\%.

5. Another conclusion from the present research was that with increasing $V_{\theta} \%$ from $32.5 \mathrm{Vol} . \%$ to $35.7 \mathrm{Vol} . \%$, wear resistance increases $4 \%$ while strength reduces less than $2.5 \%$. Hence, the studied advanced FG composite has superior wear resistance and also appropriate strength at the inner surface with density of $3.2 \mathrm{~g} / \mathrm{cm}^{3}$.

\section{References}

[1] Kieback B, Neubrand A, Riedel H. Mater. Sci. Eng. A. 2003, 362(1), 81-106.

[2] Duque NB, Melgarejo ZH, Suárez OM. Mater. Char. 2005, 55(2, 167-171.

[3] Rajan T, Jayakumar E, Pai B. Trans. Indian Inst. Metals. 2012, 65(6), 531-537.
[4] Lin X, Liu C, Xiao H. Compos. Part B: Eng. 2013, 45(1), 8-21.

[5] Zhai Y-B, Liu C-M, Kai W, Zou M-H, Yong X. Trans. Nonfer. Metals Soci. China. 2010, 20(3), 361-370.

[6] Watanabe Y, Hattori Y, Sato H. J. Mater. Proces. Tech. 2015,221, 197-204.

[7] Watanabe Y, Oike S. Acta materialia. 2005, 53(6), 1631-1641.

[8] Shailesh P, Sundarrajan S, Komaraiah M. Procedia Mater. Sci. 2014, 6, 812-820.

[9] Radhika N, Raghu R. Trans. Nonfer. Metals Soci. China. 2016, 26(4), 905-916.

[10] Chen W, Wang Q, Zai C, Ma C, Zhu Y, He W. J. mater. sci. letters. 2001, 20(9), 823-826.

[11] El-Hadad S, Sato H, Miura-Fujiwara E, Watanabe Y. Mater. 2010, 3(9), 4639-4656.

[12] Kunimine T, Shibuya M, Sato H, Watanabe Y. J. Mater. Proces. Tech. 2015, 217, 294-301.

[13] Soflaei H, Vahdat S. Arch. Found. Eng. 2016, 16(2), 99-104.

[14] Vahdat S. Arch. Found. Eng. 2016, 16(1), 131-137.

[15] Watanabe Y, Sato H, Ogawa T, Kim I-S. Mater. trans. 2007, 48(11), 2945-2952.

[16] Meetsma A, De Boer J, Van Smaalen S. J. Solid State Chem. 1989, 83(2), 370-372.

[17] Mehditabar A, Alashti RA, Pashaei M. Int.l J. Eng.-Trans. C: Aspects. 2013, 26(12), 1445.

[18] Davis J. Aluminum and aluminum alloys. ASM International. Handbook Committee. 1993.

[19] Nikhilesh C, Chawla KK. Metal matrix composites. Springer: New York, NY, USA; 2006.

[20] Madhusudan S, Sarcar MMM, Rao NBRM. J. App. Res. Tech. 2016, 14(5), 293-299.

[21] Westbrook J, Fleischer R. Intermetallic compounds.Vol. 2, Basic mechanical properties and lattice defects of intermetallic compounds: Wiley. 